Bull Earthquake Eng (2006) 4:275

DOI 10.1007/s10518-006-9011-4

ERRATUM

\title{
Modelling seismic hazard in earthquake loss models with spatially distributed exposure
}

\author{
Helen Crowley • Julian J. Bommer
}

Published online: 11 May 2006

(C) Springer Science+Business Media B.V. 2006

Unfortunately an error occurs in Figure 12 of the above-mentioned article. The two curves in the figure are incorrectly labelled. The corrected figure is provided below.

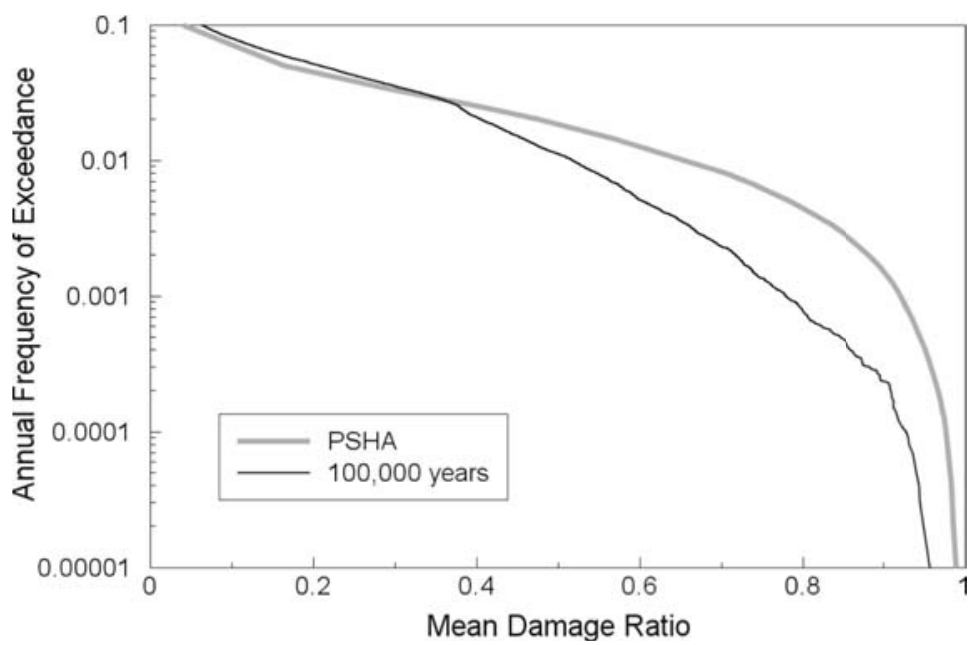

The online version of the original article can be found at http://dx.doi.org/10.1007/s10518-006-9009-y.

H. Crowley

European School for Advanced Studies in Reduction of Seismic Risk (ROSE School); c/o EUCENTRE, Via Ferrata 1, Pavia 27100, Italy

J. J. Bommer $(\varangle)$

Department of Civil and Environmental Engineering, Imperial College London,

London SW7 2AZ, UK

e-mail: j.bommer@imperial.ac.uk 